\title{
Papers
}

\section{Syphilis in pregnant women and their children in the United Kingdom: results from national clinician reporting surveys 1994-7}

\author{
A-K Hurtig, A Nicoll, C Carne, T Lissauer, N Connor, J P Webster, L Ratcliffe
}

\begin{abstract}
Objective To measure the incidence of syphilis detected in pregnancy and congenital syphilis in the United Kingdom.

Design Surveys through consultants in genitourinary medicine and paediatricians with active surveillance. Setting United Kingdom, 1994-7.

Subjects Women treated for syphilis in pregnancy, and children with early congenital syphilis born in the United Kingdom.

Results Over 3 years 139 women were diagnosed with and treated for syphilis in pregnancy; 121 were detected through antenatal screening. Thirty one had confirmed or probable congenitally transmissible syphilis, putting their pregnancies at risk. These were minimum figures but are compatible with the 90 to 100 women newly diagnosed annually as having infectious or early latent syphilis. A universal screening policy would require 18600 and 55700 women (maximum numbers) to be screened, respectively, to detect one woman needing treatment and to prevent one case of congenital syphilis. Nine presumptive cases of children with congenital syphilis born in the United Kingdom were reported. Mothers requiring treatment for syphilis were found in almost every health region but were more prevalent in London and the south east. Being born abroad and belonging to an ethnic minority group were strong risk factors, but 14\% (19 of 121) of cases treated and six of 31 definite or probably transmissible cases occurred in white women born in the United Kingdom.

Conclusions Congenitally transmissible syphilis continues to occur among pregnant women in the United Kingdom. Cases would be missed and stillbirths and congenitally infected babies would occur if antenatal screening was abandoned.
\end{abstract}

\section{Introduction}

Infectious syphilis in a pregnant woman usually results in miscarriage, stillbirth, or a congenitally infected baby. ${ }^{1}$ Risk of transmission diminishes as maternal syphilis advances, but in early latent (asymptomatic) syphilis the risk of vertical transmission remains about $30 \%$ to $60 \%$. $^{2}$ Maternal infection is, however, detectable by serological screening and entirely treatable with penicillin, which also prevents vertical transmission. ${ }^{3}$ Although screening in the United Kingdom is routine, ${ }^{2}$ there is no stated policy and the numbers of maternal cases detected are unknown. ${ }^{4}$

The number of cases of adult syphilis and childhood congenital syphilis seen at genitourinary medicine clinics in the United Kingdom diminished after $1980,{ }^{5}$ eventually resulting in calls for abandoning antenatal screening. ${ }^{4}$ The prevalence of infectious syphilis, however, has remained high in developing countries, and congenital syphilis re-emerged dramatically in the United States in the 1980s and more recently in the newly independent states of the former Soviet Union. ${ }^{2}$ The low numbers of congenital cases in the United Kingdom might be because there is no maternal syphilis or because maternal syphilis is being successfully detected and treated or because early congenital cases are seen outside genitourinary medicine clinics by paediatricians. Which of these possible explanations is correct is vital to determine an evidence based rational and efficient screening policy, particularly when screening itself has economic and social costs. ${ }^{6}$

\section{Methods}

To determine why there are low numbers of cases of congenital syphilis two national surveys (duration 1994-7) were undertaken with active surveillance; firstly, of genitourinary medicine specialists (through the British Cooperative Clinical Group) to whom most pregnant women positive for syphilis are referred for assessment and, if necessary, for treatment; and, secondly, of paediatricians (through the British Paediatric Surveillance Unit of the Royal College of Paediatrics and Child Health). ${ }^{2}{ }^{4}$ These had objectives of determining minimum incidences of pregnant women with syphilis who require treatment in pregnancy and of congenital syphilis in children born in the United Kingdom. Response rates for the surveys were over $70 \%$ and $90 \%$, respectively. Each maternal case report was reviewed and classified by two experienced physicians. Congenitally transmissible syphilis was defined as including primary, secondary, and early latent syphilis. ${ }^{2}$

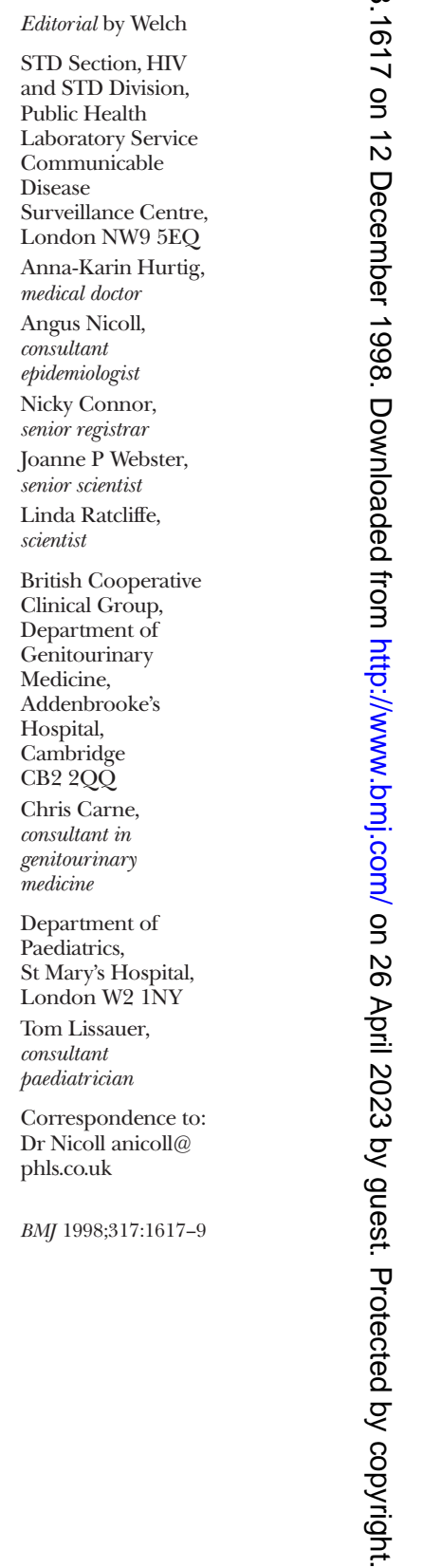


Numbers of women treated for syphilis in United Kingdom, 1994-7. Numbers detected by antenatal screening in parentheses

\begin{tabular}{|c|c|c|c|}
\hline Detail & $\begin{array}{c}\text { Congenitally } \\
\text { transmissible* }\end{array}$ & Other & Total \\
\hline Total & $31(27)$ & $108(94)$ & $139(121)$ \\
\hline \multicolumn{4}{|l|}{ Diagnostic category: } \\
\hline Primary syphilis & $1(1)$ & - & $1(1)$ \\
\hline Secondary syphilis & $4(3)$ & - & $4(3)$ \\
\hline Early latent syphilis & $26(23)$ & - & $26(23)$ \\
\hline Late latent syphilis & - & $84(71)$ & $84(71)$ \\
\hline Treated syphilis & - & $10(10)$ & $10(10)$ \\
\hline Other† or uncategorised & - & $14(13)$ & $14(13)$ \\
\hline \multicolumn{4}{|l|}{ Locationł: } \\
\hline Thames region & $20(17)$ & $81(68)$ & $101(85)$ \\
\hline Elsewhere in UK & $11(10)$ & $27(26)$ & $38(36)$ \\
\hline \multicolumn{4}{|l|}{ Ethnic group of mother§: } \\
\hline White & $11(11)$ & $22(22)$ & $33(33)$ \\
\hline Black Caribbean & $2(2)$ & $24(20)$ & $26(22)$ \\
\hline Black African & $2(2)$ & $39(33)$ & $41(35)$ \\
\hline $\begin{array}{l}\text { Indian, Pakistani, or } \\
\text { Bangladeshi }\end{array}$ & $8(7)$ & $5(5)$ & $13(12)$ \\
\hline Chinese & $2(1)$ & $4(3)$ & $6(4)$ \\
\hline Other & $5(4)$ & $10(8)$ & $15(12)$ \\
\hline Not known & $1(0)$ & $4(3)$ & $5(3)$ \\
\hline \multicolumn{4}{|l|}{ Country of birth of motherf: } \\
\hline UK & $9(8)$ & $18(18)$ & $27(26)$ \\
\hline Rest of Europe & $4(4)$ & $2(2)$ & $6(6)$ \\
\hline Russia & - & $2(2)$ & $2(2)$ \\
\hline Africa & $3(3)$ & $42(36)$ & $45(39)$ \\
\hline Caribbean & $1(1)$ & $21(17)$ & $22(18)$ \\
\hline Indian subcontinent & $6(3)$ & $3(3)$ & $9(6)$ \\
\hline Other Asia & $6(6)$ & $13(11)$ & $19(17)$ \\
\hline North America & - & $1(0)$ & $1(0)$ \\
\hline South America & $1(1)$ & $4(4)$ & $5(5)$ \\
\hline Not known & $1(1)$ & $2(1)$ & $3(2)$ \\
\hline
\end{tabular}

UK=United Kingdom

*Primary, secondary, and early latent syphilis (definite or likely).

tOther includes cases of maternal congenital syphilis (2), non-venereal treparomatoses (5).

‡National proportion of births to mothers in the Thames region=24\% (data from Office for National Statistics)

$\S$ National proportion of women aged 15-44 years of non-white ethnic groups $=6.5 \%$ (1991 census).

INational percentage of births born to mothers themselves born abroad $=13 \%$ (data from Office for National Statistics).

\section{Results}

The genitourinary medicine survey found 139 cases of women treated for syphilis in pregnancy for which data were available, 121 detected through antenatal screening (table). Thirty one (22\%) cases were categorised as definite or probable congenitally transmissible syphilis. ${ }^{2}$ The Thames regions were overrepresented $(73 \%)$, but women were treated for syphilis in pregnancy in every region, apart from East Anglia. There was also overrepresentation of ethnic minority groups and women born outside the United Kingdom, though $14 \%$ of all cases (19 of 139) and six congenitally transmissible cases were in white women born in the United Kingdom. When country of residence was reported $93 \%$ (114 of 123) were resident in the United Kingdom. When probable country of infection was reported 18 of 23 congenitally transmissible cases resulted from transmission abroad, all in developing countries and none in the former Soviet Union (table). Five women were reported as not having received any antenatal care before attending for genitourinary assessment. One woman was reported as being a commercial sex worker, and three injected drugs.
Seventeen children born in the United Kingdom were reported as meeting case definitions for congenital syphilis. ${ }^{7}$ None had definitive syphilis (which requires direct evidence of Treponema pallidum ${ }^{7}$ ), nine were presumptive, and eight were possible cases. Eight were from the Thames regions and nine from ethnic minority groups. Seven mothers had not received antenatal care or did so too late to receive treatment. Three children had clinical abnormalities; two had signs on $x$ ray pictures (one osteochondritis of the skull), and the third had hepatosplenomegaly, rhinitis, oedema, and thrombocytopenia. The three mothers had been either untreated or inadequately treated for syphilis during pregnancy. ${ }^{3}$

\section{Discussion}

These data represent a minimum incidence of congenitally transmissible syphilis in pregnant women. Reporting was incomplete; cases of late latent syphilis were excluded from the congenitally transmissible category (though transmission probably can occur from women during the late latent stage). ${ }^{2}$ Other cases would have been treated by obstetricians without referral to genitourinary medicine. ${ }^{2}$ If screening was stopped a minimum of 10 women a year with congenitally transmissible syphilis would be missed. These data are compatible with the 90-100 women newly diagnosed annually as having infectious or early latent syphilis $^{5}$ and a recent increase in transmission of heterosexual syphilis in one urban locality outside London, where four maternal cases of transmissible syphilis would have been missed if antenatal screening had not been routine. ${ }^{8}$ It is estimated that the current universal screening policy would require 18600 and 55700 women (maximum numbers), respectively, to be screened to detect a case of a woman needing treatment and to prevent one case of congenital syphilis. ${ }^{2}$ Living in the Thames regions, being of a non-white ethnic group, or being born abroad are strong risk factors. The presence of cases without any of these risk factors, however, means a selective screening programme would miss cases, even if implementation was optimal. These data indicate that current screening prevents congenital syphilis and that some fetuses and infants would be placed at risk if routine screening was stopped. It also results in the detection of women with syphilis who require treatment and the prevention of further transmission of a highly infectious sexually transmitted disease. These data are contributing to the formulation of national policy by the National Screening Committee. ${ }^{2} 6$

Permission for the surveys was given by the Public Health Laboratory Services (PHLS) Ethics Committee. Statistical advice was provided by Pauline Rogers of the PHLS statistics unit. The British Cooperative Clinician Group survey was administered in the regions by the officers and representatives of the group. We thank the specialists in genitourinary medicine and especially the regional representatives of the British Cooperative Clinician Group who made the survey of pregnant women possible. Over the period of the survey they were : G R Kinghorn (chairman); M A Waugh (former chairman); C A Carne (secretary); A McMillan; D Mandal; K R Haye; R S Pattman; A B Alawattegama; O P Arya; J Wilson; R D Maw; C O'Mahoney; K W Radcliffe; M Shahmanesh; C Bignell; J D Meaden; P K Taylor; G Luzzi; J R Isaacson; B T Goh; A G Lawrence; A de Ruiter; R N Thin; A T Nayagam; F E Wilmott; W Harris; D Mercey; and W Dinsmore. Dr Beng Goh (London Hospital) and Dr Adam 
Key messages

- Infectious syphilis and other forms of congenitally transmissible syphilis continue to be found among pregnant women in the United Kingdom

- New cases of infectious syphilis are being detected through antenatal screening

- Risk factors for infectious syphilis in pregnant women comprise living in London and the south east, belonging to an ethnic minority group, and having been born abroad

- A substantial minority of mothers with congenitally transmissible syphilis also occur among white women born in the United Kingdom

- Abandonment of universal screening for syphilis would probably result in stillbirths and cases of congenital syphilis

Lawrence (Chelsea and Westminster Hospital) were the syphilis specialists who reviewed the cases, and we thank them for their speedy turn round of case reports. We acknowledge the diligence of individual specialists in genitourinary medicine and paediatricians in returning cards and data.

Contributors: A-KH undertook the analysis of the data and drafted the paper. AN designed and oversaw the running of the surveys and completed the paper. CC led and coordinated the
British Cooperative Clinical Group survey and contributed to the writing of the paper, as did TL, who was the lead clinician for the survey of paediatricians. NC contributed to writing the paper and applying the findings to syphilis screening policy. JW and LR administered the two surveys. AN is the guarantor.

Funding: The British Paediatric Surveillance Unit (BPSU) is part of the Research Division of the Royal College of Paediatricians and Child Health (RCPCH) and was supported at the time of the survey by a grant from Children Nationwide. Administration of the surveys was supported by the PHLS through core funding from the Department of Health.

Competing interests: None declared.

1 Schwartz DA, Larsen SA, Beck-Sague C, Fear M, Rice RJ. Pathology of the umbilical cord in congenital syphilis analysis of 25 specimens using histochemistry and immunofluorescent antibody to Treponema pallidum. Hum Pathol 1995;26:784-91.

2 STD Section, HIV and STD Division, PHLS Communicable Disease Surveillance Centre, with the PHLS Syphilis Working Group. Report to the National Screening Committee. Antenatal syphilis screening in the UK-a systematic review and national options appraisal with recommendations. London: Public Heath Laboraty Service, 1998.

3 Centers for Disease Control and Prevention. 1998 Guidelines for treatment of sexually transmitted diseases. MMWR 1998;47. (Recommendation and reports (RR-1).)

4 Nicoll A, Moisley C. Antenatal screening for syphilis. $B M J$ 1994;308:1253-4

5 Communicable Disease Surveillance Centre. Sexually transmitted diseases quarterly report: syphilis in England and Wales. CDR Weekly $1997: 7: 192-4$

6 Calman K. Developing screening in the NHS. J Med Screening 1994;1:

7 Centers for Disease Control and Prevention. Case definitions for infectious conditions under public health surveillance. MMWR 1997;46. (Recommendation and reports (RR-10).)

8 Anonymous. Syphilis in Bristol 1997-8: an update. CDR Weekly $1998 ; 8: 413,416$

(Accepted 7 August 1998)

\section{Prospective study of post-traumatic stress disorder in children involved in road traffic accidents}

Paul Stallard, Richard Velleman, Sarah Baldwin

\author{
Abstract \\ Objective To determine the prevalence of severe \\ psychological trauma - that is, post-traumatic stress \\ disorder-in children involved in everyday road traffic \\ accidents. \\ Design 12 month prospective study. \\ Setting Accident and emergency department, Royal \\ United Hospital, Bath. \\ Subjects 119 children aged 5-18 years involved in \\ road traffic accidents and 66 children who sustained \\ sports injuries. \\ Main outcome measure Presence of appreciable \\ psychological distress; fulfilment of diagnostic criteria \\ for post-traumatic stress disorder. \\ Results Post-traumatic stress disorder was found in 41 \\ $(34.5 \%)$ children involved in road traffic accidents but \\ only two $(3.0 \%)$ who sustained sports injuries. The \\ presence of post-traumatic stress disorder was not \\ related to the type of accident, age of the child, or the \\ nature of injuries but was significantly associated with \\ sex, previous experience of trauma, and subjective \\ appraisal of threat to life. None of the children had \\ received any psychological help at the time of \\ assessment
}

Conclusions One in three children involved in road traffic accidents was found to suffer from post-traumatic stress disorder when they were assessed 6 weeks after their accident. The psychological needs of such children after such accidents remain largely unrecognised.

\section{Introduction}

Accidents in children are common and in 1996 in the United Kingdom accounted for about two million presentations at accident and emergency departments. ${ }^{1}$ Parental reports indicate that most children display emotional distress immediately after an accident, although for most this distress is short lived and comparatively mild. Questionnaires completed by children indicate that some experience higher levels of emotional distress, particularly those involved in road traffic accidents or who have fallen from heights. This distress can persist for several months, although the emotional needs of these children are rarely recognised and seldom receive any ongoing planned intervention. ${ }^{1}$

In 1997 the number of road traffic accidents involving young people under the age of 19 years
Department of Child and Family Psychiatry, Bath Mental Health Care Trust, Royal United Hospital, Bath BA1 3NG

Paul Stallard, clinical psychologis Richard Velleman, director of research and development Sarah Baldwin, research assistant

Correspondence to: Dr Stallard stallard_p@bath-mhct. swest.nhs.uk

BMJ 1998;317:1619-23 